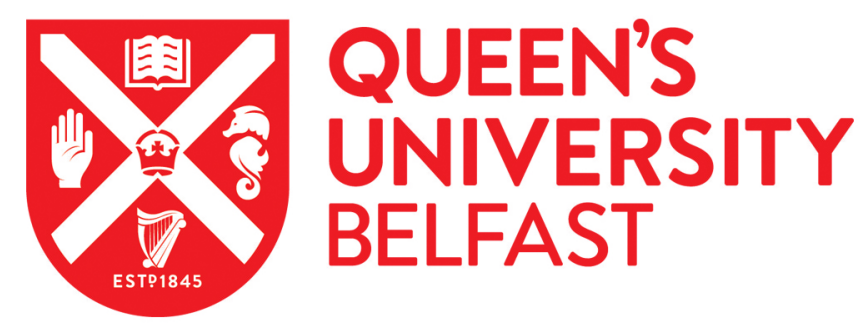

\title{
Surface Morphology and In Vitro Bioactivity of Biocompatible Hydroxyapatite Coatings on Medical Grade S31254 Steel by RF Magnetron Sputtering Deposition
}

Das, A., \& Shukla, M. (2017). Surface Morphology and In Vitro Bioactivity of Biocompatible Hydroxyapatite Coatings on Medical Grade S31254 Steel by RF Magnetron Sputtering Deposition. Transactions of the IMF The International Journal of Surface Engineering and Coatings , 95(5), 276-281.

https://doi.org/10.1080/00202967.2017.1323675

\section{Published in:}

Transactions of the IMF - The International Journal of Surface Engineering and Coatings

\section{Document Version:}

Peer reviewed version

Queen's University Belfast - Research Portal:

Link to publication record in Queen's University Belfast Research Portal

\section{Publisher rights}

Copyright 2017 Taylor \& Francis.

This work is made available online in accordance with the publisher's policies. Please refer to any applicable terms of use of the publisher.

\section{General rights}

Copyright for the publications made accessible via the Queen's University Belfast Research Portal is retained by the author(s) and / or other copyright owners and it is a condition of accessing these publications that users recognise and abide by the legal requirements associated with these rights.

Take down policy

The Research Portal is Queen's institutional repository that provides access to Queen's research output. Every effort has been made to ensure that content in the Research Portal does not infringe any person's rights, or applicable UK laws. If you discover content in the

Research Portal that you believe breaches copyright or violates any law, please contact openaccess@qub.ac.uk. 


\title{
Surface Morphology and In Vitro Bioactivity of Biocompatible Hydroxyapatite Coatings on Medical Grade S31254 Steel by RF Magnetron Sputtering Deposition
}

\author{
Ashish Das ${ }^{\mathrm{a}}$, Mukul Shukla ${ }^{\mathrm{a}, \mathrm{b}, \mathrm{c}}$ \\ ${ }^{a}$ Department of Mechanical Engineering \\ MNNIT, Allahabad, 211004, India \\ ashishdas.1110@gmail.com \\ ${ }^{b}$ School of Mechanical and Aerospace Engineering \\ Queen's University, Belfast, BT9 5AH, Northern Ireland, UK \\ 'Department of Mechanical Engineering Technology \\ University of Johannesburg, Johannesburg, 2028, South Africa \\ mukulshukla@mnnit.ac.in,m.shukla@qub.ac.uk,mshukla@uj.ac.za
}

*Corresponding author - Mukul Shukla

Tel: +44-7827858184; Fax: +44-28-90974148; E-mail: mukulshukla2k@gmail.com

\begin{abstract}
Hydroxyapatite (HA) is popularly used as a bio-compatible coating material for metallic implants, in view of its improved bone fixation property, leading to an increased life of the implant. However, the deposition of HA on medical grade UNS S31254 stainless steel (SS254) for orthopaedic implant applications by the radio-frequency magnetron sputtering technique is unreported in the literature so far. The surface morphology of deposited HA coatings was characterized using Scanning Electron Microscopy and Atomic Force Microscopy, while their phase composition was determined using X-ray Diffraction. The thickness and adhesive strength of the HA coatings were determined using an Ellipsometer and a Tensometer, respectively. Finally, the antibacterial efficacy and bioactivity of the deposited coatings were confirmed using Fluorescence Activated Cell Sorting and Immersion test in Simulated Body Fluid environment. The obtained results showed that the HA coatings grown on SS254 using magnetron sputtering possess desirable surface properties as well as adhesion and biocompatibility properties, ideally suited for potential applications in orthopaedic implants.
\end{abstract}

Keywords

Coating; hydroxyapatite; magnetron sputtering; 254 stainless steel; implant. 


\section{Introduction}

In spite of the lower corrosion resistance when compared to titanium, internal fixation devices are still being made of austenitic stainless steels (largely SS 316L). This is owing to their excellent mechanical properties and comparative low cost [1-2]. Lately, newer generation of steels with superior corrosion resistance and mechanical properties are being studied [3-7]. For orthopaedic implants ISO 5832-9 SS is being used, in comparison to F138-92 SS as it does not undergo pitting corrosion [8-12]. Likewise, UNS S31254 SS (254 SS) also exhibits high resistance against hydrochloric acid [9] and phosphoric acid [10], and in chloride media it does not exhibit pitting at room temperature [9]. Absence of toxic effect as confirmed by cytotoxicity results and high nitrogen content of 254 SS have made it a candidate material for scientific investigation, towards developing futuristic implant materials [1112].

Hydroxyapatite (HA) holds a significant position as an inorganic biomaterial. However, bulk HA ceramics possess poor mechanical properties, restricting its use for load bearing implant applications. To overcome this limitation, HA coating is being deposited on metals and their alloys, to derive the dual advantage of bioactivity of HA and mechanical performance of metals [13]. HA is widely coated on orthopaedic implants because its mechanical properties closely resemble to those of human bones and it is also biocompatible with human bone tissues [14]. HA coating of orthopaedic implants can be an effective method of improving the physiological response of the implant surface leading to an overall improved performance of the implants [15].

HA coatings can be deposited on a metallic substrate using various techniques, such as direct laser melting, sol-gel, electro deposition, dip coating, ion beam, pulsed laser deposition and various other vapor deposition processes, including plasma spray which is a commercially viable technique for clinical applications [15-22]. Plasma spraying produces bioactive ceramic coatings with high adhesion strength, but this technique also has many demerits such as chemical in-homogeneity and variable crystalline nature of coating [16-18]. The Magnetron Sputtering (MS) technique has emerged as an alternative to the aforesaid methods owing to its flexibility of depositing a variety of materials. This technique facilitates the deposition of dense, well-adhered films with controlled elemental composition [23] by appropriate selection of deposition parameters (target feed power, gas flow rate, working pressure, substrate temperature, deposition time, substrate bias voltage etc.) [20]. In order to obtain HA coatings with better bioactivity properties, a good control of their morphology, surface roughness and crystallinity is essential 
[20]. The major drawback of MS, however, is that it produces HA coatings with low crystallinity, requiring postdeposition annealing heat treatment [24]. With this background motivation, this study is focused on the improvement of protective and osteogenic performance of a new generation of medical grade stainless steel (S31254), with an aim of yielding a superior bio-implant material. This is achieved by coating HA on S31254 steel, employing the MS technique. Limited studies of this nature are available in the literature [25] making it a novel research.

\section{Material and methods}

The MS technique, its basic principle and construction of equipment have been described elsewhere [26-29]. In this research, the coatings were fabricated using a RF magnetron sputtering unit (Hind High Vacuum Co. (P) Ltd, Model: RF/DC sputtering unit). HA targets (of $50 \mathrm{~mm}$ diameter and $2 \mathrm{~mm}$ thickness) were prepared from HA powder (supplied by Clarion Pharmaceutical Co., New Delhi, India of the following properties $(\mathrm{Ca} / \mathrm{P}$ molar ratio $=$ 1.61-1.71, Calcium $=32-36 \%$, Phosphorus $=18-22 \%$, Moisture $=<5 \%$, Mesh size $=100 \%$ passing 100 mesh, Visual appearance $=$ White powder) as per the standard procedure adopted in [14]. The UNS S31254 sheet of dimensions $10 \times 10 \times 2 \mathrm{~mm}^{3}$ was used as a substrate. Before introducing the substrates (in group of four) inside the deposition chamber, they were polished and cleaned with acetone to remove surface contaminants. Based on preliminary trials and literature review the deposition parameters were set as follows: base pressure $=5.8 \times 10^{-6}$ mbar, chamber pressure $=3.5 \times 10^{-2} \mathrm{mbar}$, substrate temperature $=$ room temperature, deposition time $=90 \mathrm{~min}$, target fed power $=$ $250 \mathrm{~W}$, argon flow rate $=15 \mathrm{sccm}$ (standard cubic centimeter per minute), distance between target and substrate $=5$ cm [26-27, 29-30]. The as-deposited films had thickness of nearly $213 \pm 37 \mathrm{~nm}$. In order to restore the initial crystalline status, the amorphous coatings obtained by deposition were finally annealed for $2 \mathrm{~h}$ at $600{ }^{\circ} \mathrm{C}$ in ambient air.

Thereafter, the surface morphology of the HA coatings was examined using Scanning Electron Microscopy (SEM; Zeiss Model: EVO15) and Atomic Force Microscopy (AFM; Agilent Technologies Model: 5500). The phase composition of HA coatings was determined using X-ray diffraction (XRD; Rigaku Model: Smart lab $3 \mathrm{~kW}$ ) and the coating thicknesses was measured using an Ellipsometer. The adhesive strength of HA coatings was determined using a Tinius Olsen Tensometer while their antibacterial efficacy was determined using the Fluorescence Activated Cell Sorting (FACS) technique, which is one of the best, modern technologies for cell sorting [31]. Lastly, the 
bioactivity of HA coatings was established by conducting an immersion test in Simulated Body Fluid (SBF) environment.

\section{Results and discussion}

\subsection{Surface morphology}

Fig. 1 shows the SEM micrographs of the surface morphology of the uncoated UNS S31254 substrate and asdeposited HA thin film grown by the RF magnetron sputtering process. In comparison to the bare surface, a dense, crack and other defects free coating was evident on the entire substrate surface. Parallel grooved lines resulting due to substrate grinding are clearly visible on the surface. A similar surface morphology was reported by Thian et al [32].

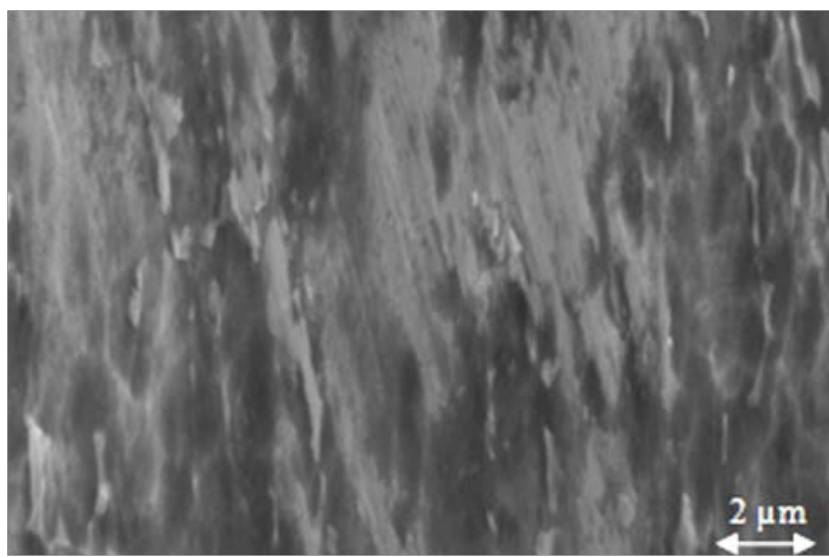

(a)

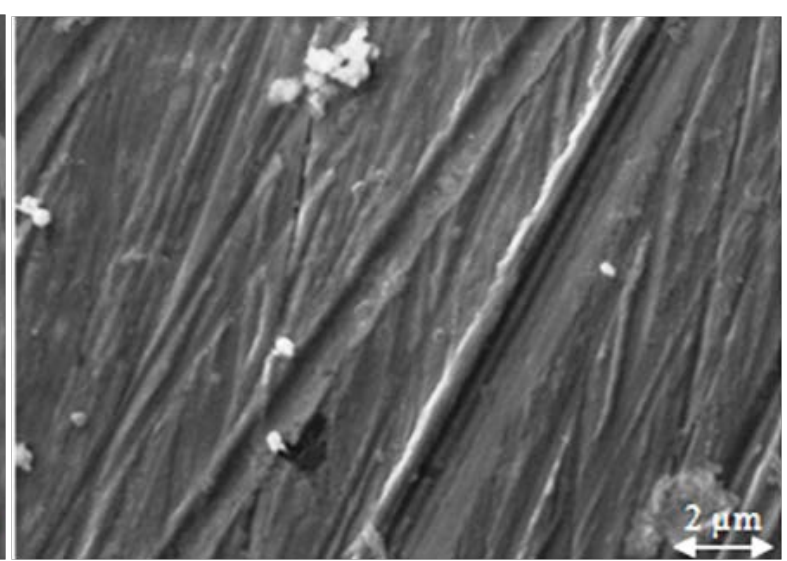

(b)

Fig. 1 SEM micrographs of (a) uncoated and (b) HA coated UNS S31254substrate.

Fig. 2 shows the Xray diffractograms of bare UNS S31254, HA target, HA coating and annealed HA coating. The XRD peaks of bare UNS S31254 appear at $2 \theta$ values of $43.4^{\circ}$ and $50.2^{\circ}$. While those of HA target and both HA coatings and annealed HA coatings appear at $31.88^{\circ}$. During deposition no stoichiometric changes in HA were evident owing to the relatively high mean-free-path length at low operating pressure of $10^{-2} \mathrm{mbar}$ [28]. The obtained diffraction peaks match well with those available in the literature [33] and found to be in agreement, confirming the presence of crystalline HA phase in the coating (along with minor traces of amorphous phase). The peak of substrate material (Fe) appeared at $2 \theta=43.4^{\circ}$ which indicates minor non-uniformity in the coating. 
After post deposition annealing, the crystallinity and coating uniformity increases, as confirmed by the intensity of the peaks and published literature [14]. The intensity of the $31.88^{\circ}$ HA peak increases by approximately $20 \%$ while the $43.4^{\circ}$ Fe peak decreases by about $58 \%$, results in increased crystallinity of HA coatings. The crystallinity of ceramic coatings is directly linked to the coatings solubility (i.e. life) within the physiological environment. Hence, mineral coatings need to be maximally crystalline in order to perform optimally in vivo [29].

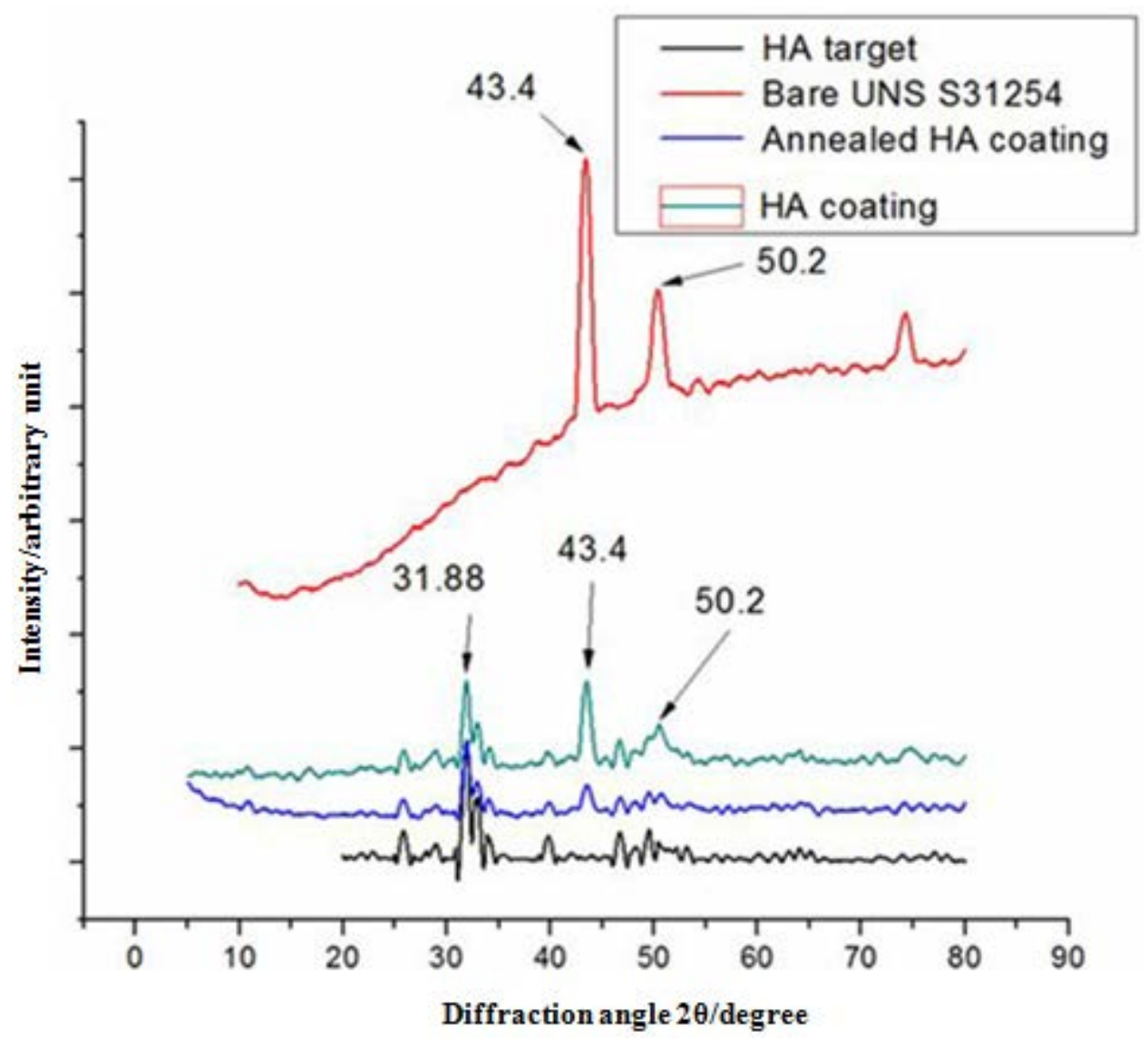

Fig. 2 Xray diffractograms of bare UNS 31254, HA target, HA coated and annealed HA coated substrate.

The $1 \times 1 \mu \mathrm{m}^{2}$ AFM micrographs presented in Fig. 3 are used for investigating the surface morphology of uncoated UNS S31254 substrate and HA coating. The average surface roughness of the uncoated UNS S31254 substrate was found to be nearly $1.35 \mathrm{~nm}$. The 3D morphology of the coated substrate shown in Fig. 3 (b) reveals the formation of valleys on the surface of the deposited films. These valleys increase the average surface roughness of the coating to nearly $4.98 \mathrm{~nm}$ which is higher than the $2.6 \mathrm{~nm}$ roughness reported by Lopez et al [34]. It is already well established that human osteoblasts attach more readily to surfaces with a roughness less than $500 \mathrm{~nm}$ than to surfaces with a 
roughness greater than $2000 \mathrm{~nm}$ [35]. Hence, the human osteoblasts are also likely to attach readily to our HA coating surface.
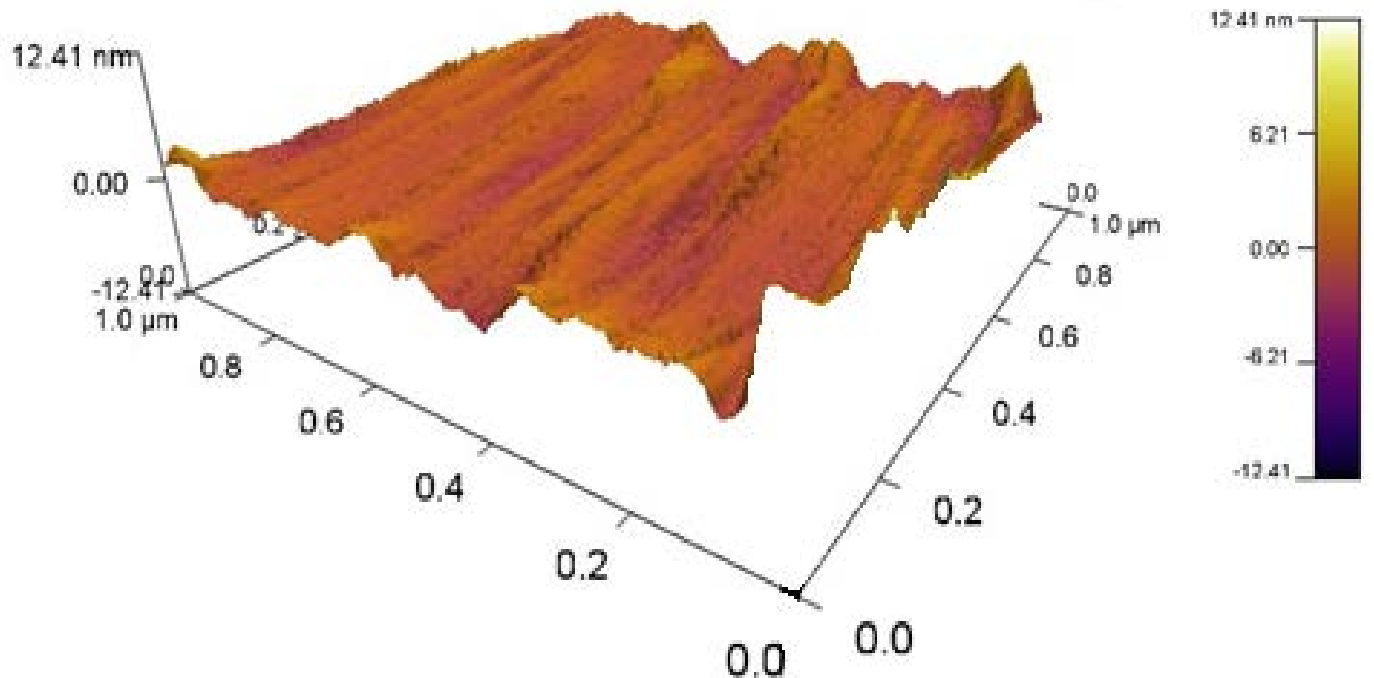

(a)
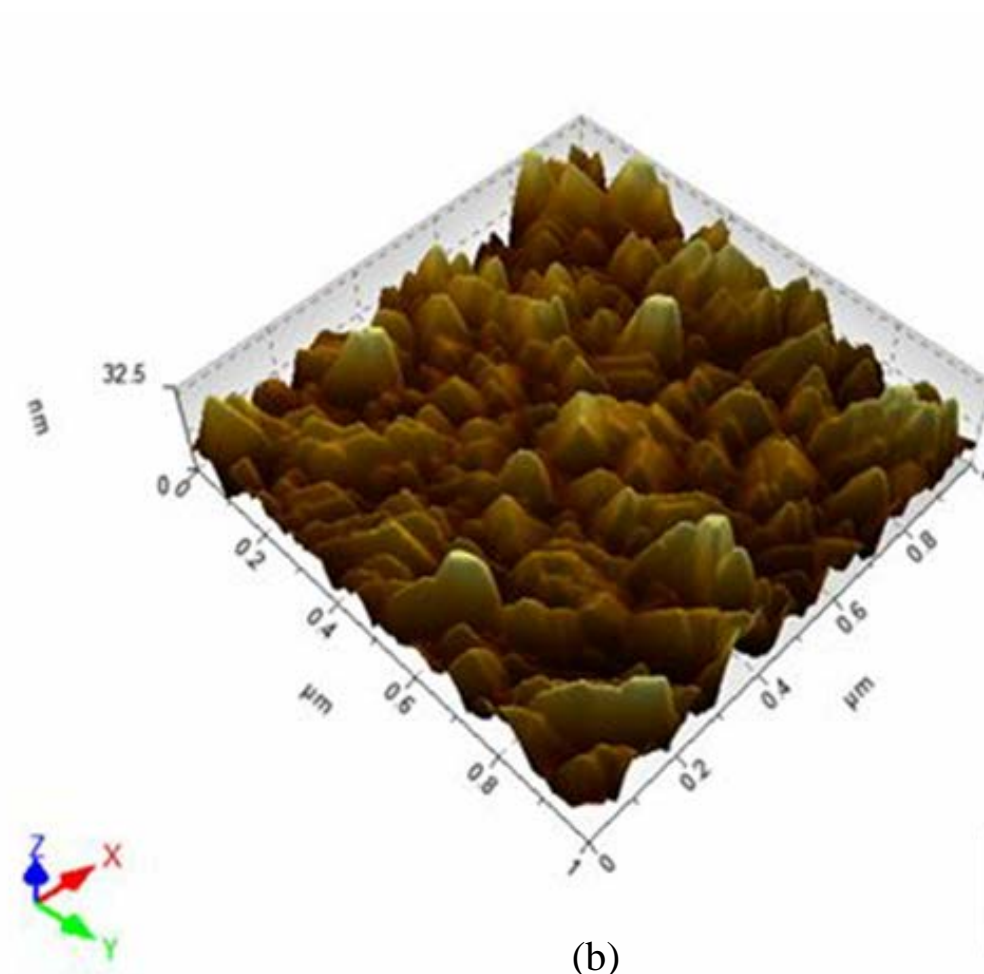

(b)

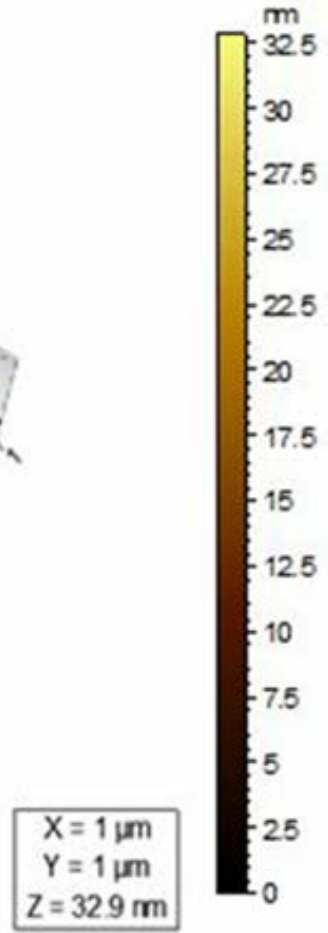

Fig. 3 3D AFM micrographs of UNS S31254 (a) uncoated and (b) HA coated substrate. 


\subsection{Adhesive strength}

The adhesive strength of HA coatings was tested by conducting tensile pull out tests (as per ASTM C633 standard) on a Tinius Olsen tensometer. Fig. 4 represents a schematic of the tensile pull out test for determination of adhesion strength. The test includes the attachment of a stainless steel stud (of dimensions $10 \mathrm{~mm} \times 10 \mathrm{~mm} \times 50.8 \mathrm{~mm}$ ) to the HA coated surface using Epoxy Adhesive (EpoFix Resin and EpoFix Hardener), cured at room temperature for $48 \mathrm{~h}$. After installing the coated sample/stud assembly on the tensometer, the stud was pulled in tensile mode until failure. The average adhesive strength of HA coatings (over three samples) was found to be $22.32 \pm 3.7 \mathrm{MPa}$ [28] which is higher than the standard value of 15 MPa according to ISO 13779-2 [36]. The results obtained above can be attributed to the operating pressure of $10^{-2}$ mbar required to maintain high ion energies).

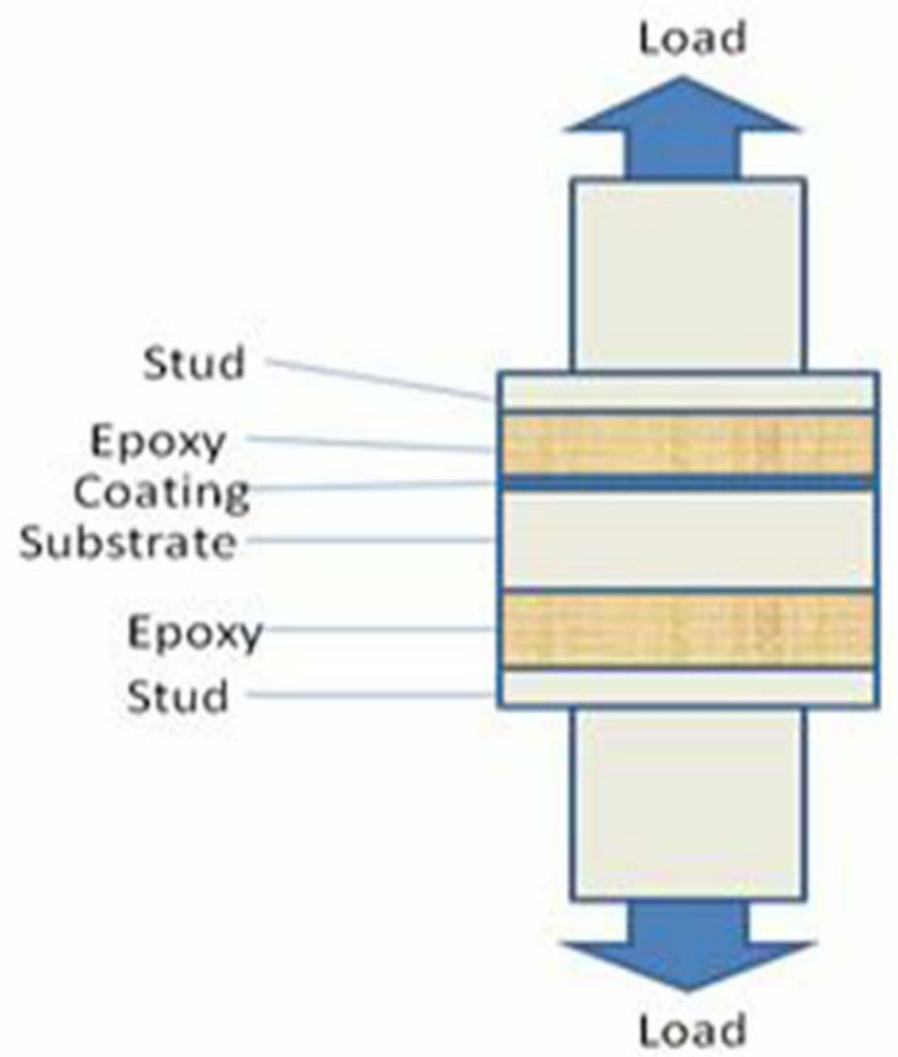

Fig. 4 Schematic of adhesive testing.

The SEM micrograph of Fig. 5 shows that epoxy failure was the dominant failure mode during the pull-off test, with $70-80 \%$ of the failed area falling under this mode, indicating that the bond strength of coatings is superior to that of 
the epoxy. The higher bonding strength of the HA coatings produced in this work can also be attributed to the uniformly distributed, higher values of surface roughness.

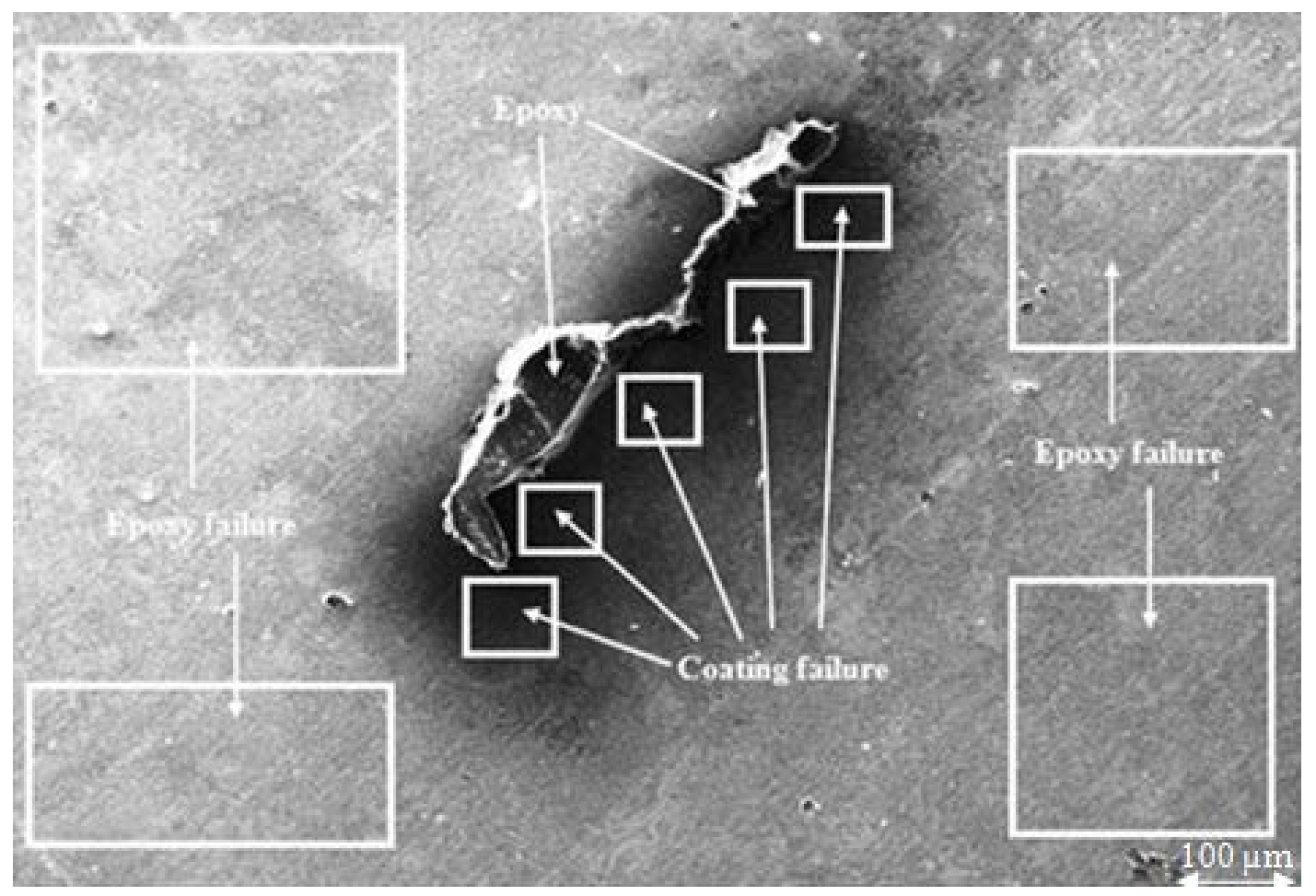

Fig. 5 SEM micrograph of HA coated sample after tensile pull out test.

\subsection{Antibacterial efficacy}

The in vitro antibacterial efficacy of the bare and HA coated samples was investigated against Escherichia coli (E. coli) by using the Fluorescence activated cell sorting (FACS) technique, in order to confirm the reattainment of antibacterial property in HA coatings deposited employing the radio-frequency magnetron sputtering, which is essential to overcome the skin-seal problem of such implants [36]. The inoculum of the E. coli microorganisms was prepared from fresh broth cultures incubated at $37^{\circ} \mathrm{C}$ with constant stirring and used in sample preparation for FACS. The FACS samples were prepared by adopting the methodology as already given by the authors in [25].

Fig. 6 (a) shows the FACS results in terms of Forward Scattering (FSC) and Side Scattering (SSC) for the bare sample (FSC $=60,955.19$, SSC $=28,683.32$ ), while Fig. 6 (b) shows for the HA coated sample (FSC $=41,644.73$, SSC $=11,870.98$ ). They show a decrease in size (by FSC) and granularity (by SSC), of the E. coli micro-organisms, 
for the HA coated sample, with respect to the bare sample. Hence, the FACS results confirm the death of E. coli in HA coated sample, This in turn confirms the inhibition of possible infection in the body part surrounding the nearby surface of metallic implant, reducing the bacteria adhesion and promoting bone tissue formation [38].

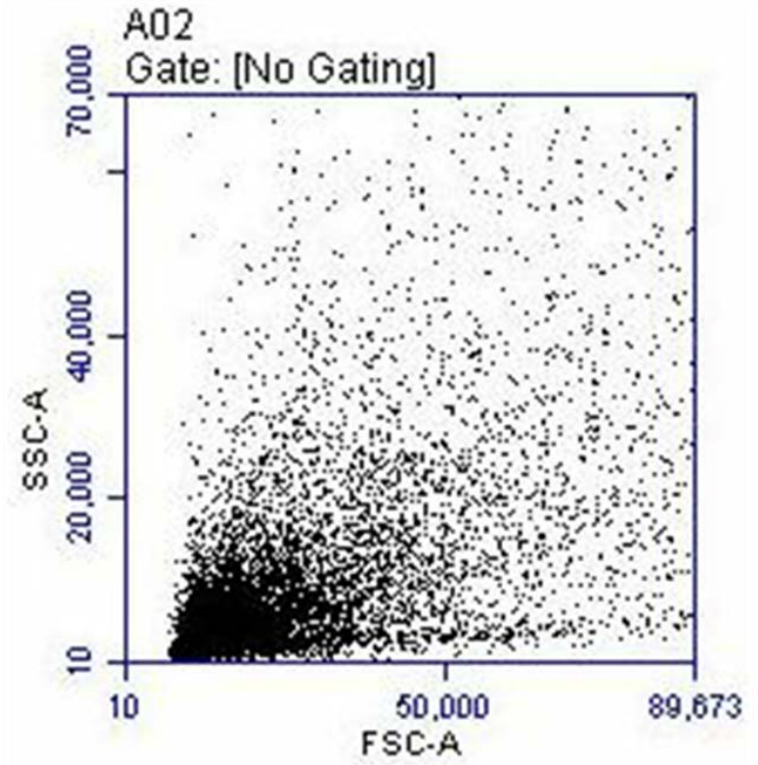

(a)

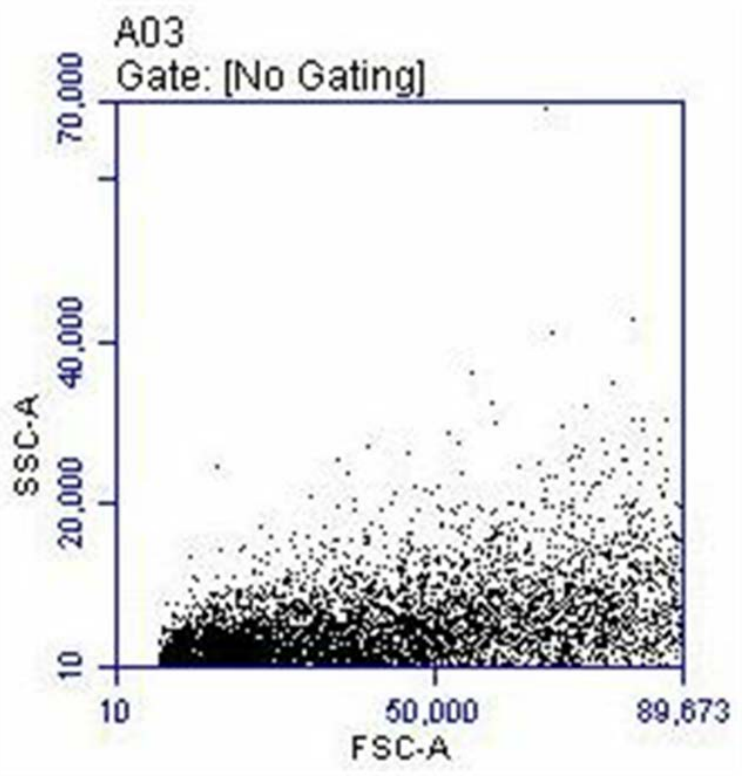

(b)

Fig. 6 FACS graphs (a) bare sample and (b) HA coated sample.

\subsection{Bioactivity}

Bioactivity of HA coated substrate was investigated by conducting immersion test in SBF. The as-fabricated HA coated substrate was first washed with acetone and then with deionized water, and dried in an oven to remove traces of moisture. An in vitro bone-like layer growth test was performed by immersing the samples (approximate size 10 $\times 10 \times 2 \mathrm{~mm}^{3}$ ) in $30 \mathrm{ml}$ of SBF in a poly-ethylene bottle and maintained at $36.5^{\circ} \mathrm{C}$ for 28 days with continuous stirring at $800 \mathrm{rpm}$, without refreshing the SBF solution [39].

The detailed preparation, chemical composition and pH of SBF adopted in this study were followed as per [40]. Fig. 7 shows the surface morphology of the HA coated substrate after immersion in SBF, at two different magnifications (1000 and 2500). From Fig. 7b the growth of apatite layers is clearly visible; resulting in an average increase of nearly $0.06 \%$ in the weight of HA coated substrate, after the immersion test [41]. Previous studies have shown that 
formation of biological apatite on the surface of artificial bioactive materials is critical to establishing bonding between living tissue and biomaterials [42]. The formation mechanism of apatite on the surface of HA compacts after soaking in SBF may be attributed to the ion exchange between HA compacts and the SBF solution [43]. The bonding mechanism of bioactive materials to living tissues involves a sequence of eleven successive reaction steps [44-45]. The growth of apatite during 28 days of immersion in SBF is comparatively much more rapid with respect to the overall life (5-10 years) of an implant, confirming that the HA coated surface produced in our research is more bioactive, when compared to the bare SS254 implant and thus promotes more osseointegration [41].

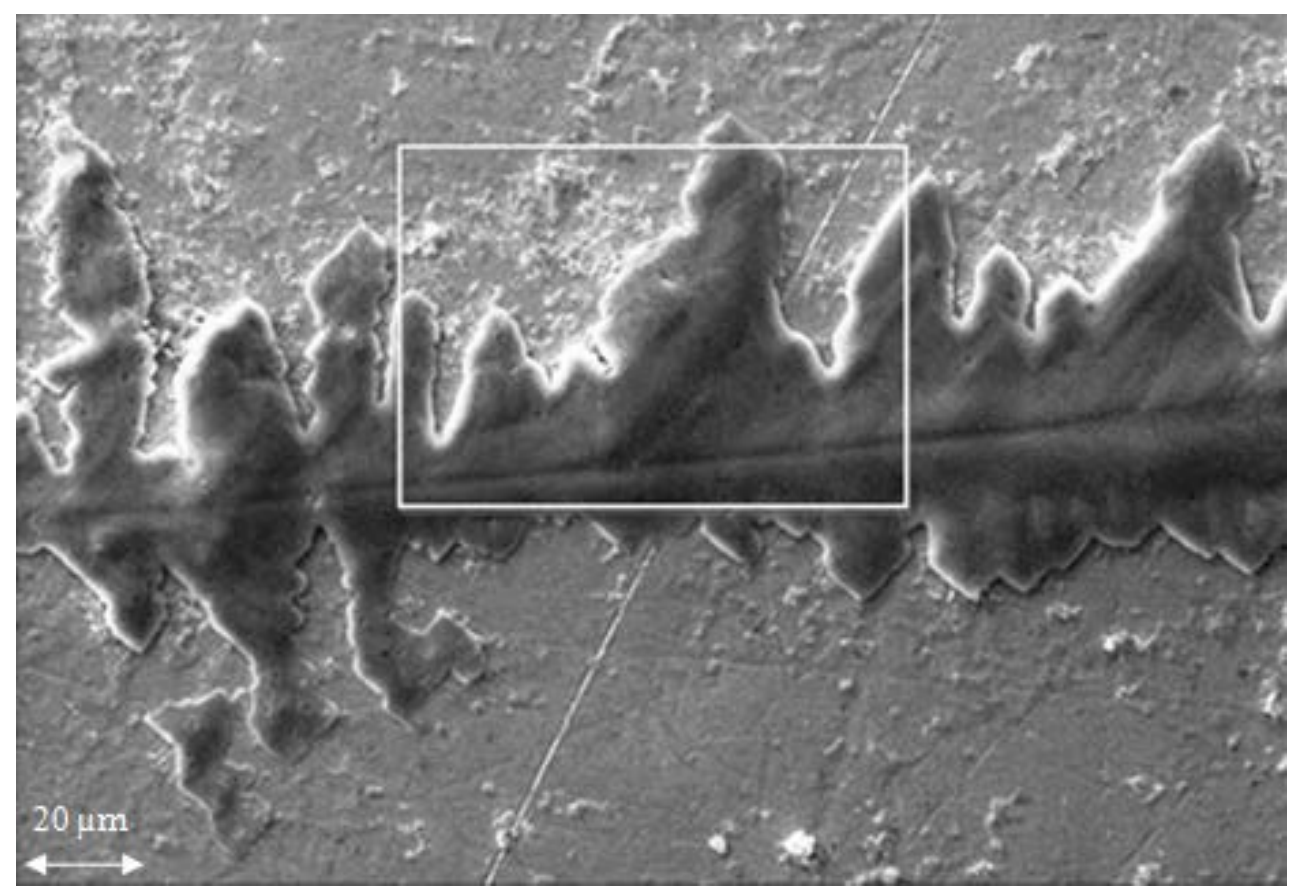

(a) 


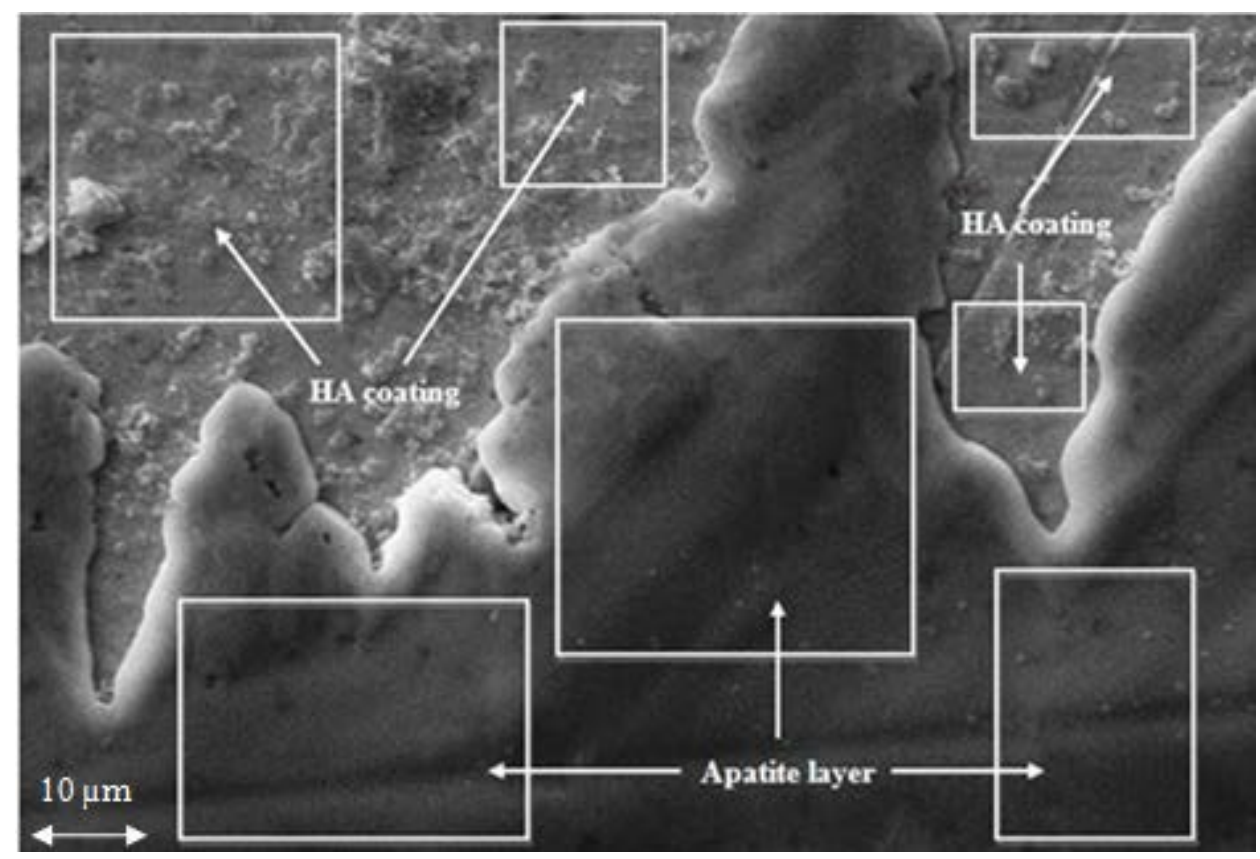

(b)

Fig. 7 SEM micrographs of HA coated sample after immersion test at (a) 1000X and (b) 2500X.

\section{Conclusions}

In this research columnar HA coatings were successfully deposited on UNS S31254 substrate using the radiofrequency magnetron sputtering. Post deposition annealing was found to be beneficial to achieve the desired crystallinity and uniformity in the coatings. SEM results ensure that coatings were dense and free from defects. AFM results confirm the increase in surface roughness of coatings which is desirable for increased cell growth and proliferation. The adhesive strength of coatings obtained was higher than the standard and their superior antibacterial properties and bioactivity was also confirmed. This research goes on to establish an alternate process route to improve the physiological behavior of UNS S31254, a new generation (higher nitrogen content) and cheaper (vis-a-vis titanium) grade of stainless steel, by coating hydroxyapatite using the MS technique. The promising results obtained are in line with the requirements for an improved orthopaedic implant material.

\section{Acknowledgements}

The use of synthesis, testing and characterization facilities of the Centre for Interdisciplinary Research (CIR), Centre for Medical Diagnostic and Research (CMDR), Biotechnology and Applied Mechanics Departments, MNNIT, 
Allahabad are gratefully acknowledged. Thanks are also due to Dr Naresh Kumar and Mr. Aashish Jha for their valuable contribution in the experimental work. The authors would like to thank the Ministry of Human Resource Development, Government of India and the University of Johannesburg, South Africa for providing financial support.

References

[1] J.A. Disegi and L. Eschbach L: Injury, 2000, 4, 2-6.

[2] J. Walczac, F. Shahgaldi and F. Heartley: Biomaterials, 1998, 19(1-3), 229-237.

[3] R.F.V.V. Jaimes, M.L.C.A Afoson, S.O. Rogero, S.M.L. Agostinho and C.A. Barbosa: Materials Letters, 2010, 64(13), 1476-1479.

[4] E. Salahinejad, M.J. Hadianfard, D.D. Macdonald, S. Sharifi-Asl, M. Mozafari, K.J. Walker, T.A. Rad, S.V. Madihally and L. Tayebi: PLoS ONE, 2013, 8(4), 616-633.

[5] S.F. Rodrigues, E.S. Silva, G.S. Reis, R.C. Sousa and O. Balancin: Materials Research, 2014, 17(2), 436-444.

[6] E.J. Giordani, V.A. Guimaraes, T.B. Pinto and I. Ferreira: International Journal of Fatigue, 2004, 26(10), 1129-1136.

[7] A.F. Padilha, I.F. Machado and R.L. Plaut: Journal of Materials Processing Technology, 2005, 170(1-2), 8996.

[8] R.F.V. Villamil, A.H.P. Andrade, C.A. Barbosa, A. Sokolowski and S.M.L. Agostinho: Stainless Steels for Medical and Surgical Applications, 2003, 168-75.

[9] L. Michelli, A.H.P. Andrade, C.A. Barbosa and S.M.L. Agostinho: British Corrosion Journal, 1999, 34(1), 67-70.

[10] R. Qvarfort: Corrosion Science 1989, 29(2), 987-993. 
[11] M.L.C.A. Afonso, J.R.F.V. Villamil, E.P.G. Areas, M.R. Capri, E. Oliveira and S.M.L Agostinho: Colloids and Surfaces. A, Physicochemical and Engineering Aspects, 2008, 317(1-3), 760-763.

[12] M.L.C.A. Afonso, R.F.V.V. Jaimes, P.A.P. Nascente, S.O. Rogero and S.M.L. Agostinho: Materials Letters, 2015, 148, 71-75.

[13] Q. Bao , C. Chen , D. Wang , Q. Ji and T. Lei: Applied Surface Science, 2005, 252(5), 1538-1544.

[14] H. Khandelwal, G. Singh, K. Agrawal, S. Prakash and R.D. Agarwal: Applied Surface Science, 2013, 265, 30-35.

[15] V. Nelea, C. Morosanu, M. Iliescu and I.N. Mihailescu: Surface and Coatings Technology, 2003, 173(2-3), 315-322.

[16] J. Wen , Y. Leng, J. Chen and C. Zhang: Biomaterials, 2000, 21(13), 1339-1343.

[17] L. Yan , Y. Leng and L.T. Weng: Biomaterials, 2003, 24(15), 2585-2592.

[18] S.F.J. Garcia, M.B. Mayor, J.L. Arias, J. Pou, B. Leon and A.M. Perez: Journal of Materials Science: Materials in Medicine, 1997, 8(12), 861-865.

[19] M. Tlotleng, E. Akinlabi, M. Shukla and S. Pityana: Materials Science and Engineering: C, 2014, 43, 189198.

[20] R.A. Surmenev: Surface and Coatings Technology, 2012, 206(8-9), 2035-2056.

[21] M. Saremi and B.M. Golshan: Transactions of the IMF: The International Journal of Surface Engineering and Coatings, 2007, 85(2), 99-102.

[22] C.S. Chien, Y.S. Ko, T.Y. Kuo, T.Y. Liao, H.C. Lin, T.M. Lee and T.F. Hong: Journal of Medical and Biological Engineering, 2015, 35(3), 357-366.

[23] J. Z. Shi, C. Z. Chen, H. J. Yu and S. J. Zhang: Bulletin of Materials Science, 2008, 31(6), 877-884.

[24] Y. Yang, K. H. Kim and J. L. Ong: Biomaterials, 2005, 26(3), 327-337. 
[25] A. Das and M. Shukla: Journal of Materials: Design and Applications, 2016, doi: 10.1177/1464420716663029.

[26] S. Zhang: Hydroxyapatite Coatings for Biomedical Applications, CRC Press Taylor \& Francis Group, 2013.

[27] A. William: Handbook of sputtering Technology, Elsevier, 2012.

[28] S. Swann: Magnetron Sputtering, Physics Technology, 1988, 19, 67-75.

[29] M. Driver: Coatings for Biomedical Applications, Woodhead Publishing Limited, 2012.

[30] W. Tao: Bio-Medical Materials and Engineering, 2007, 17(5), 291-297.

[31] R. Wolkowicz: Fluorescence-Activated Cell Sorting, Brenner's Encyclopedia of Genetics, Academic Press 2013, Second Edition, 80-82.

[32] E.S. Thian, J. Huang, S. M. Best, Z. H. Barber and W. Bonfield: Biomaterials, 2005, 26(16), 2947-2956.

[33] L.Q. Tri and D.H.C. Chua: Applied Surface Science, 2009, 256, 76-80.

[34] E.O. Lopez, A. Mello, H. Sendao, L.T. Costa, A.L. Rossi, O.R. Ospina, F.F. Borghi, J.G.S. Filho and A.M.M. Rossi: ACS Applied Materials and Interfaces, 2013, 5(19), 9435-9445.

[35] K. Anselme, M. Bigerelle, B. Noel, E. Dufresne, D. Judas, A. Iost and P. Hardouin: Journal of Biomedical Materials Research, 2000, 49(2), 155-166.

[36] ISO 13779-2:2008, ISO Implants for surgery-hydroxyapatite- Part 2: Coating of hydroxyapatite.

[37] X. Ge, Y. Leng, C. Bao, S.L. Xu, R. Wang and F. Ren: Journal of Biomedical Materials Research A, 2010, 95(2), 588-599.

[38] S.D. Puckett, E. Taylor, T. Raimondo and T.J. Webster: Biomaterials, 2010, 31(4), 706-713.

[39] W. Yi, X. Sun, D. Niu and X. Hu: Journal of Asian Ceramic Societies, 2014, 2(3), 210-214.

[40] T. Kokubo and H. Takadama: How useful is SBF in predicting in vivo bone bioactivity? Biomaterials, 2006, 27(15), 2907-2915. 
[41] H.C. Man, K.Y. Chiu, F.T. Cheng and K.H. Wong: Adhesion study of pulsed laser deposited hydroxyapatite coating on laser surface nitrided titanium, Thin Solid Films, 2009, 517(18), 5496-5501.

[42] M. Neo, S. Kotani, T. Nakamura, T. Yamamuro, C. Ohtsuki, T. Kokubo and Y.A. Bando: Journal of Biomedical Material Research, 1992, 26(11), 1419-1432.

[43] Y.W. Gu, K.A. Khor and P. Cheang: Biomaterials, 2004, 25(18), 4127-4134.

[44] L.L. Hench: Journal of the American Ceramic Society, 1998, 81(7), 1705-1728.

[45] L.L. Hench, D.E. Day, W. Holand and V.M. Rheinberger: International Journal of Applied Glass Science, 2010, 1(1), 104-117. 